\title{
Association between resting heart rate and coronary artery disease, stroke, sudden death and noncardiovascular diseases: a meta-analysis
}

\author{
Dongfeng Zhang MD, Weijing Wang MD, Fang Li MD \\ Infographic available at www.cmaj.ca/lookup/suppl/doi:10.1503/cmaj.160050/-/DC2
}

Competing interests:

None declared.

This article has been peer reviewed.

Accepted: Apr. 13, 2016 Online: Aug. 22, 2016

Correspondence to:

Dongfeng Zhang,

zhangdf1961@126.com

CMAJ 2016. DOI:10.1503/ cmaj.160050

\begin{abstract}
- Abstract
Background: Resting heart rate is linked to risk of coronary artery disease, stroke, sudden death and noncardiovascular diseases. We conducted a meta-analysis to assess these associations in general populations and in populations of patients with hypertension or diabetes mellitus.

Methods: We searched PubMed, Embase and MEDLINE from inception to Mar. 5, 2016. We used a random-effects model to combine studyspecific relative risks (RRs). We used restricted cubic splines to assess the dose-response relation.

Results: We included 45 nonrandomized prospective cohort studies in the meta-analysis. The multivariable adjusted RR with an increment of 10 beats/min in resting heart rate was 1.12 (95\% confidence interval [CI] 1.09-1.14) for coronary artery disease, $1.05(95 \% \mathrm{Cl} 1.01-$ 1.08) for stroke, $1.12(95 \% \mathrm{Cl} 1.02-1.24)$ for sudden death, $1.16(95 \% \mathrm{Cl} 1.12-1.21)$ for noncardiovascular diseases, $1.09(95 \% \mathrm{Cl} 1.06-$ 1.12) for all types of cancer and $1.25(95 \% \mathrm{Cl}$ 1.17-1.34) for noncardiovascular diseases

excluding cancer. All of these relations were linear. In an analysis by category of resting heart rate $(<60$ [reference], $60-70,70-80$ and $>80$ beats $/ \mathrm{min})$, the RRs were $0.99(95 \% \mathrm{Cl}$ $0.93-1.04), 1.08(95 \% \mathrm{Cl} 1.01-1.16)$ and 1.30 (95\% Cl 1.19-1.43), respectively, for coronary artery disease; 1.08 (95\% Cl 0.98-1.19), 1.11 $(95 \% \mathrm{Cl} 0.98-1.25)$ and $1.08(95 \% \mathrm{Cl} 0.93-$ 1.25), respectively, for stroke; and 1.17 (95\% Cl $0.94-1.46), 1.31$ (95\% Cl 1.12-1.54) and 1.57 (95\% Cl 1.39-1.77), respectively, for noncardiovascular diseases. After excluding studies involving patients with hypertension or diabetes, we obtained similar results for coronary artery disease, stroke and noncardiovascular diseases, but found no association with sudden death.

Interpretation: Resting heart rate was an independent predictor of coronary artery disease, stroke, sudden death and noncardiovascular diseases over all of the studies combined. When the analysis included only studies concerning general populations, resting heart rate was not associated with sudden death.
\end{abstract}

$\mathrm{H}$ eart rate reflects the balance of sympathetic and parasympathetic activity, and is influenced by several nonmodifiable and modifiable factors. ${ }^{1}$ High natural resting heart rate is associated with traditional risk factors for cardiovascular diseases, levels of inflammatory markers ${ }^{2-4}$ and functional decline, ${ }^{5}$ which suggests that resting heart rate might be related to the risk of various disease states. We previously found that resting heart rate was an independent predictor of total mortality related to cardiovascular disease in the general population. ${ }^{6}$ However, the predictive values of resting heart rate for cardiovascular-specific outcomes, including coronary artery disease, stroke and sudden death, as well as noncardiovascular diseases, have not been quantified in the general population. Although the potential importance of resting heart rate has been recognized, ${ }^{7}$ it has not been included for cardiovascular risk assessment in European and US guidelines ${ }^{7,8}$ because the benefit of a reduction in resting heart rate for noncardiac patients is unknown. In addition, the magnitude of associations between resting heart rate and the abovementioned outcomes varies across studies, and the optimal resting heart rate can be expected to differ with disease state. ${ }^{9}$ Therefore, we conducted a meta-analysis of prospective cohort studies, in accordance with the PRISMA checklist (Appendix 1, available at www.cmaj.ca/lookup/ suppl/doi:10.1503/cmaj.160050/-/DC1), to quantitatively assess these associations in general populations and in populations of patients with hypertension and diabetes mellitus. 


\section{Methods}

\section{Literature search and study selection}

Two investigators (D.Z., W.W.) identified articles independently through a systematic search of PubMed, Embase and MEDLINE from inception to Mar. 5, 2016, and by searching the reference lists of selected articles. The search was restricted to studies involving humans and published in English or Chinese. Details of the search strategy and results are presented in Appendix 2 (available at www.cmaj.ca/lookup/ suppl/doi:10.1503/cmaj.160050/-/DC1). There was no protocol for this meta-analysis.

Two investigators (D.Z., F.L.) independently selected studies using the following criteria: the participants were from the general population or were patients with hypertension or diabetes (excluding studies in cardiac patients); the exposure of interest was resting heart rate; the outcome of interest was coronary artery disease, stroke, sudden death, noncardiovascular diseases, all types of cancer or noncardiovascular diseases excluding cancer; the study reported relative risks (RRs) or hazard ratios with $95 \%$ confidence intervals (CIs), with all current results being presented as RRs; and the study had a prospective cohort design. If the same data were reported in more than one study, we included the study with the longest follow-up duration.

\section{Data extraction}

Two investigators (W.W., F.L.) independently extracted the following data using a standardized data collection form: first author's name, year of publication, country where the study was conducted, duration of follow-up, participants' age, sample size, sex, number of events, method of measuring resting heart rate, adjusted covariables, health status of participants at baseline and RR (with $95 \% \mathrm{CI}$ ) for each category of resting heart rate. We extracted the RRs that reflected the most inclusive but significant adjustment for potential confounders.

\section{Statistical analysis}

Detailed information about the analysis is available in our previous paper. ${ }^{6}$ In brief, we combined study-specific logarithms of RRs for an increment of 10 beats/min in resting heart rate using a random-effects model. We used the $I^{2}$ statistic to evaluate between-study heterogeneity. We conducted subgroup analyses and metaregression to explore potential sources of heterogeneity and to perform comparisons between groups. We performed a sensitivity analysis and evaluated publication bias. We assessed study quality using the 9-star Newcastle-Ottawa Scale (www.ohri.ca/programs/clinical_epidemiology/ oxford.asp).

We also conducted a 2-stage random-effects dose-response meta-analysis. ${ }^{10}$ Where cases were missing from a given category, we inferred the data from the total numbers of cases and the reported risk estimates. ${ }^{11}$ In separate analyses, according to the threshold level of resting heart rate in the general population ( $80-85$ beats $/ \mathrm{min})^{12}$ and the cut-offs used in the included studies, we combined the resting heart rate categories into 4 groups: reference (lowest category in each study, i.e., $<60$ beats $/ \mathrm{min}), 60-70,70-80$ and $>80$ beats $/ \mathrm{min}$. We did not conduct this analysis for sudden death, all cancers or noncardiovascular diseases excluding cancer because of the relatively small number of studies. All statistical analyses were performed with STATA version 12.0. All reported probabilities ( $p$ values) were 2 -sided, with $p<0.05$ considered significant.

\section{Results}

Literature search and study characteristics After exclusion of nonrelevant and duplicate articles, 523 records were reviewed in full. Another 478 records were excluded for other reasons (Appendix 2), and 45 prospective cohort studies were included in this meta-analysis. Of the 45 studies ( 38 studies in general populations and 7 studies in populations of patients with hypertension or diabetes), 30 provided results for coronary artery disease (1 227511 participants and 18364 cases), 17 provided results for stroke (1 002667 participants and 11515 cases), 12 provided results for noncardiovascular diseases (443 192 participants and 12749 cases), 10 provided results for all types of cancer (115 388 participants and 5714 cases), 7 provided results for noncardiovascular diseases excluding cancer (81 332 participants and 2174 cases), and 7 provided results for sudden death (426332 participants and 563 deaths). The follow-up duration ranged from 2 to 40 years. The study quality ranged from 5 to 9 stars (Appendix 3, available at www.cmaj.ca/lookup/suppl/doi:10.1503/cmaj .160050/-/DC1). Detailed information about the included studies appears in Appendix 4 (available at www.cmaj.ca/lookup/suppl/doi:10.1503/ cmaj.160050/-/DC1).

\section{Quantitative synthesis}

\section{Cardiovascular-specific diseases}

The multivariable-adjusted RR for coronary artery disease with every increment in resting heart rate of 10 beats $/ \mathrm{min}$ was 1.12 (95\% CI $1.09-1.14 ; P^{2}=$ $10.3 \%$; Figure $1^{13-41}$ ). There was no evidence of 
Study

Benetos et al. ${ }^{14}(\mathrm{~W})$

Aladin et al. ${ }^{32}$ (M)

Reunanen et al. ${ }^{16}$ (M)

Aladin et al. ${ }^{32}(\mathrm{~W})$

Gillman et al. ${ }^{37}(\mathrm{~W})$

Poulter et al. ${ }^{41}$

Greenland et al. ${ }^{15}$ (M)

Hansen et al. 22

Adabag et al. ${ }^{21}$

Mai et al. ${ }^{25}$

Nauman et al. ${ }^{31}$

Ho et al. ${ }^{34}$

Greenland et al. ${ }^{15}$ (W)

Reunanen et al. ${ }^{16}$ (W)

Okamura et al. ${ }^{18}$ (W)

Tverdal et al. ${ }^{23}(\mathrm{~W})$

Julius et al. 39

Wang et al. ${ }^{35}$

Gillman et al. 37 (M)

Benetos et al. ${ }^{14}(\mathrm{M})$

Tverdal et al. ${ }^{23}(\mathrm{M})$

Nauman et al. ${ }^{29}$ (M)

Hsia et al. ${ }^{24}$

Nauman et al. ${ }^{29}(\mathrm{~W})$

Mao et al. ${ }^{28}(\mathrm{~W})$

Floyd et al. ${ }^{33}$

Mao et al. ${ }^{28}(\mathrm{M})$

Legeai et al. ${ }^{30}$

Kado et al. ${ }^{17}$

Woodward et al. ${ }^{36}$

Paul et al. ${ }^{38}$

Okamura et al. ${ }^{18}(\mathrm{M})$

Cooney et al. ${ }^{27}$ (M)

Jouven et al. ${ }^{19}$

Savonen et al. ${ }^{20}$

Batty et al. ${ }^{26}$

Shaper et al. ${ }^{13}$

Cooney et al. ${ }^{27}$ (W)

Stettler et al. 40

Overall $\left(I^{2}=10.3 \%\right)$
$\operatorname{RR}(95 \% \mathrm{Cl})$

0.87 (0.54-1.41)

0.99 (0.89-1.10)

1.01 (0.86-1.18)

$1.01(0.88-1.16)$

1.04 (0.89-1.23)

1.04 (0.96-1.13)

1.04 (0.95-1.14)

1.06 (0.95-1.19)

1.07 (0.93-1.23)

1.07 (0.78-1.47)

1.07 (0.79-1.44)

$1.07(0.97-1.19)$

1.07 (0.98-1.17)

1.08 (0.84-1.39)

1.10 (0.68-1.77)

$1.10(0.98-1.23)$

1.10 (1.04-1.27)

$1.10(1.01-1.20)$

$1.11(1.00-1.23)$

$1.12(0.93-1.34)$

1.12 (1.06-1.18)

1.12 (0.97-1.30)

1.14 (1.01-1.29)

1.14 (1.08-1.20)

1.14 (1.07-1.21)

1.14 (0.94-1.39)

1.16 (1.10-1.23)

$1.16(0.82-1.65)$

1.17 (1.05-1.30)

1.18 (1.03-1.35)

$1.20(0.85-1.70)$

$1.21(1.00-1.46)$

1.22 (1.11-1.33)

1.23 (1.05-1.45)

1.26 (1.01-1.58)

1.27 (0.85-1.89)

1.28 (0.89-1.85)

1.31 (1.12-1.54)

1.52 (1.21-1.90)

1.12 (1.09-1.14)

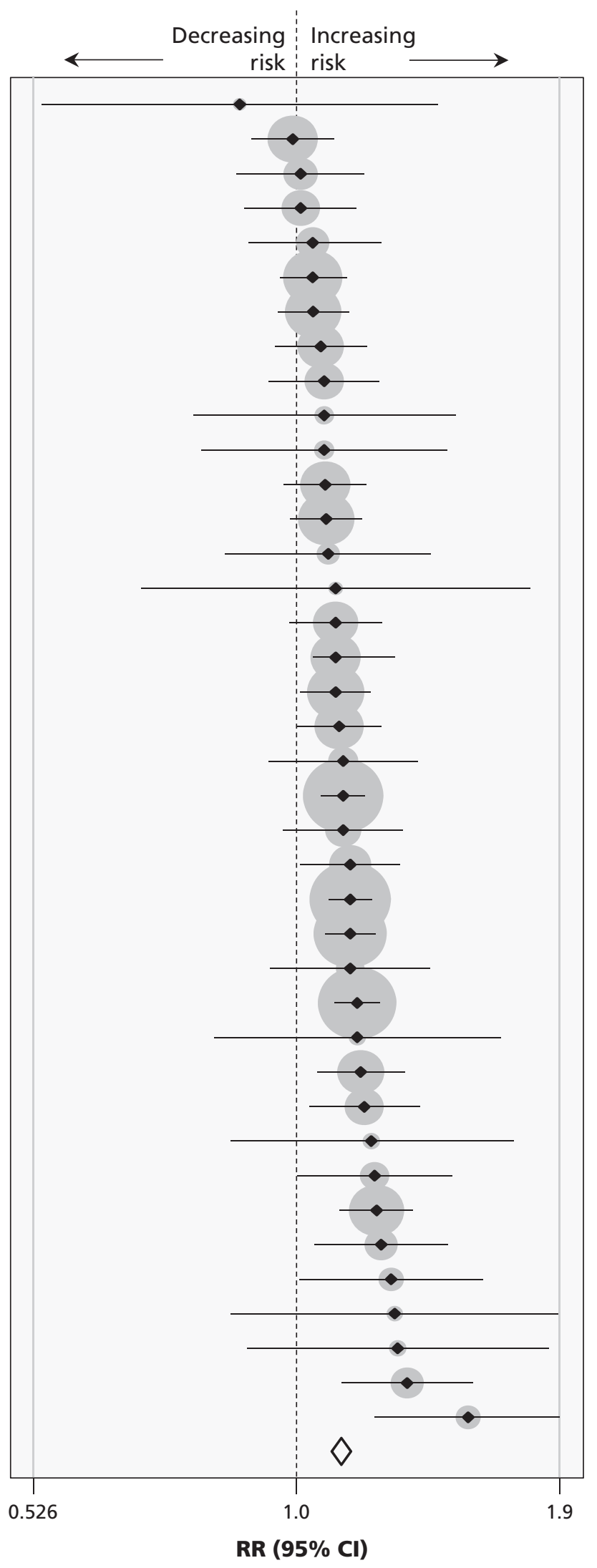

Figure 1: Forest plot of each increment in resting heart rate of 10 beats/min in relation to risk of coronary artery disease. The size of each grey circle is proportional to the weight assigned to that study. Covariable-adjusted risk estimates were used because the raw numbers were not provided in the original studies. Note: $\mathrm{Cl}=$ confidence interval, $\mathrm{M}=\mathrm{men}, \mathrm{RR}=$ relative risk, $\mathrm{W}=\mathrm{women}$. 
publication bias $(p=0.8)$. Relative to those with resting heart rate below 60 beats/min, the RR for coronary artery disease was 0.99 (95\% CI 0.93 1.04) for those with resting heart rate of 60-70 beats/min, 1.08 (95\% CI 1.01-1.16) for those with resting heart rate of $70-80$ beats/min and 1.30 (95\% CI 1.19-1.43) for those with resting heart rate above 80 beats/min (Table 1 ).

The multivariable-adjusted RR of stroke with every increment in resting heart rate of 10 beats/ min was 1.05 (95\% CI 1.01-1.08; $\left.I^{2}=48.6 \%\right)$ (Table 2). There was no evidence of publication bias $(p=0.9)$. Relative to those with resting heart rate below 60 beats/min, the RR for stroke was 1.08 (95\% CI 0.98-1.19) for those with resting heart rate of $60-70$ beats/min, 1.11 (95\% CI 0.98 1.25) for those with resting heart rate of $70-80$ beats/min and 1.08 (95\% CI 0.93-1.25) for those with resting heart rate above 80 beats $/ \mathrm{min}$.

The multivariable-adjusted RR of sudden death with every increment in resting heart rate of 10 beats/min was 1.12 (95\% CI $1.02-1.24 ; l^{2}=$ $50.3 \% ; n=8)$. There was no evidence of publication bias $(p=0.7)$.

\section{Noncardiovascular diseases}

The multivariable-adjusted RR for noncardiovascular diseases with every increment in resting heart rate of 10 beats/min was 1.16 (95\% CI 1.12 $1.21 ; P^{2}=64.9 \%$; Figure $2^{14,22,23,30,42-48}$ ). There was some evidence of publication bias $(p=0.05)$. Relative to those with resting heart rate below 60 beats/min, the RR for noncardiovascular diseases was 1.17 (95\% CI 0.94-1.46) for those with resting heart rate of 60-70 beats/min, 1.31 (95\% CI 1.12-1.54) for those with resting heart rate of 70-80 beats/min and 1.57 (95\% CI 1.39-1.77) for those with resting heart rate above 80 beats/min.

The multivariable-adjusted RR for all types of cancer with every increment in resting heart rate of 10 beats/min was 1.09 (95\% CI 1.06$1.12 ; I^{2}=0.00 \%$ ) (Table 2). There was no evidence of publication bias $(p=0.4)$.

The multivariable-adjusted RR for noncardiovascular diseases excluding cancer with every increment in resting heart rate of 10 beats/ min was 1.25 (95\% CI $\left.1.17-1.34 ; I^{2}=67.7 \%\right)$ (Table 2). There was no evidence of publication bias $(p=0.4)$.

\section{Sensitivity analysis, subgroup analysis and meta-regression}

No individual study had an excessive influence on the pooled effect in a sensitivity analysis. We assessed confounding by the following 8 traditional risk factors for cardiovascular diseases:

Table 1: Pooled results for risk of coronary artery disease, by resting heart rate (reference: $<60$ beats/min)

\begin{tabular}{|c|c|c|c|c|c|c|c|c|}
\hline \multirow[b]{2}{*}{ Variable } & \multicolumn{2}{|c|}{$60-70$ beats/min } & \multicolumn{2}{|c|}{$70-80$ beats/min } & \multicolumn{2}{|c|}{$>80$ beats $/ \mathrm{min}$} & \multicolumn{2}{|c|}{10 beats/min increment } \\
\hline & $n$ & $\operatorname{RR}(95 \% \mathrm{Cl})$ & $n$ & $\operatorname{RR}(95 \% \mathrm{Cl})$ & $n$ & $\operatorname{RR}(95 \% \mathrm{Cl})$ & $n$ & $\operatorname{RR}(95 \% \mathrm{Cl})$ \\
\hline \multicolumn{9}{|l|}{ Mean age } \\
\hline$>50 \mathrm{yr}$ & 10 & $1.02(0.95-1.09)$ & 13 & $1.09(1.02-1.18)$ & 15 & $1.28(1.14-1.43) \ddagger$ & 23 & $1.11(1.08-1.14)$ \\
\hline \multicolumn{9}{|c|}{$\begin{array}{l}\text { Absence of CVD at } \\
\text { baseline }\end{array}$} \\
\hline Yes & 13 & $0.99(0.92-1.06)$ & 16 & $1.07(0.97-1.17)$ & 22 & $1.28(1.14-1.42) \ddagger$ & 26 & $1.12(1.10-1.15)$ \\
\hline No & 3 & $0.91(0.73-1.15)$ & 7 & $1.15(1.02-1.29)$ & 7 & $1.37(1.18-1.60)$ & 13 & $1.10(1.06-1.15)$ \\
\hline \multicolumn{9}{|l|}{ Sex } \\
\hline \multicolumn{9}{|c|}{$\begin{array}{l}\text { No. of covariables* adjusted } \\
\text { for in meta-regression } \dagger\end{array}$} \\
\hline$\geq 6$ & 9 & $1.05(0.97-1.14)$ & 10 & $1.21(1.07-1.37)$ & 15 & $1.47(1.27-1.69)$ & 22 & $1.13(1.10-1.17)$ \\
\hline$<6$ & 7 & $0.93(0.86-1.00)$ & 13 & $1.00(0.93-1.07)$ & 14 & $1.19(1.07-1.32) \ddagger$ & 17 & $1.10(1.08-1.13)$ \\
\hline \multicolumn{9}{|c|}{$\begin{array}{l}\text { Note: } \mathrm{Cl}=\text { confidence interval, } \mathrm{CVD}=\text { cardiovascular disease, } n=\text { number of studies with sex-specific results that were included in the analysis, RR }=\text { relative risk. } \\
\text { *Covariables were blood pressure, smoking, body mass index, physical activity, serum cholesterol or triglycerides, diabetes mellitus and blood glucose, alcohol } \\
\text { use, and education or social class. } \\
\text { tAll associations determined by "meta-regression were nonsignificant }(p>0.05) \text {, except for the subgroup analysis by number of covariates adjusted for in the } \\
\text { categories of "70-80 beats/min" and "> } 80 \text { beats } / \text { min." } \\
\text { fHeterogeneity was moderate }\left(l^{2} \text { value between } 50 \% \text { and } 75 \%\right) \text {. For RR values without this symbol, heterogeneity was low }\left(l^{2}<50 \%\right) \text {. }\end{array}$} \\
\hline
\end{tabular}


blood pressure, smoking, body mass index, physical activity, serum cholesterol or triglycerides, diabetes or blood glucose level, alcohol use, and education or social class, all of which are correlated with heart rate. ${ }^{2}$ Overall, meta-regression and subgroup analysis showed that these traditional risk factors for cardiovascular diseases, the methods of measuring heart rate and the population characteristics did not contribute significantly to heterogeneity in most of the analyses (Appendix 5, available at www.cmaj.ca/lookup/suppl/ doi:10.1503/cmaj.160050/-/DC1). Similar results were obtained in a sensitivity analysis that excluded studies involving patients with hypertension or diabetes, but no association was found with sudden death.

In particular, to exclude the potential influence of heart rate-lowering medications and disease states on the associations, we performed a sensitivity analysis that included only participants without cardiovascular disease at baseline. In this sensitivity analysis, the multivariable-adjusted RR with every increment in resting heart rate of 10 beats/min was 1.12 (95\% CI 1.10-1.15) for coronary artery disease, 1.05 (95\% CI 1.00-1.10) for stroke, 1.16 (95\% CI 1.10-1.22) for noncardiovascular diseases,
1.07 (95\% CI 1.02-1.11) for all types of cancer and 1.23 (95\% CI 1.13-1.35) for noncardiovascular diseases excluding cancer.

\section{Dose-response analysis with restricted cubic spline functions}

The departure from a linear relation with resting heart rate was not significant for risk of coronary artery disease (15 studies, ${ }^{13,14,16,21,23,24,26,28-32,35,36,49}$ $p$ for nonlinearity $=0.05$, Figure $3 \mathrm{~A})$, stroke (10 studies, ${ }^{14,16,23,24,26,28,35,36,50,51} p$ for nonlinearity $>0.9$ ), noncardiovascular diseases (8 studies, ${ }^{14,23,30,42-45,49} p$ for nonlinearity $=0.2$, Figure 3B), cancer (6 studies, ${ }^{16,26,42,45,52,53} p$ for nonlinearity $=0.9)$, noncardiovascular diseases excluding cancer (3 studies, ${ }^{16,18,42} p$ for nonlinearity $=0.4$ ) and sudden death ( 3 studies, ${ }^{13,21,23}$ $p$ for nonlinearity $=0.6$ ). When we used the lowest value in the included studies (49 beats/min) as the reference level, the risk of noncardiovascular diseases and of all types of cancer increased significantly with increasing levels of resting heart rate in a linear relation, but a significantly increased risk of coronary artery disease was observed at about 80 beats $/ \mathrm{min}$ (Appendix 6, available at www.cmaj.ca/lookup/ suppl/doi:10.1503/cmaj.160050/-/DC1).

Table 2: Pooled risk of stroke, noncardiovascular diseases, all types of cancer and noncardiovascular diseases excluding cancer with increment of 10 beats/min in resting heart rate*

\begin{tabular}{|c|c|c|c|c|c|c|c|c|}
\hline \multirow[b]{2}{*}{ Variable } & \multicolumn{2}{|r|}{ Stroke } & \multicolumn{2}{|c|}{$\begin{array}{c}\text { Noncardiovascular } \\
\text { diseases }\end{array}$} & \multicolumn{2}{|c|}{ All types of cancer } & \multicolumn{2}{|c|}{$\begin{array}{c}\text { Noncardiovascular } \\
\text { diseases excluding cancer }\end{array}$} \\
\hline & $n$ & RR $(95 \% \mathrm{Cl})$ & $n$ & RR $(95 \% \mathrm{Cl})$ & $n$ & RR $(95 \% \mathrm{Cl})$ & $n$ & RR $(95 \% \mathrm{Cl})$ \\
\hline Overall & 20 & $1.05(1.01-1.08)$ & 13 & $1.16(1.12-1.21) \ddagger$ & 15 & $1.09(1.06-1.12)$ & 12 & $1.25(1.17-1.34) \ddagger$ \\
\hline \multicolumn{9}{|l|}{ Mean age } \\
\hline$>50 \mathrm{yr}$ & 15 & 1.06 (1.02-1.09) & 9 & $1.19(1.11-1.27) \ddagger$ & 7 & $1.10(1.06-1.15)$ & 6 & $1.28(1.15-1.42) \ddagger$ \\
\hline \multicolumn{9}{|c|}{$\begin{array}{l}\text { Absence of CVD at } \\
\text { baseline }\end{array}$} \\
\hline Yes & 12 & $1.05(1.00-1.10) \ddagger$ & 4 & $1.16(1.10-1.22) \ddagger$ & 7 & $1.07(1.02-1.11)$ & 6 & $1.23(1.13-1.35)$ \\
\hline No & 8 & $1.05(1.01-1.10)$ & 9 & $1.18(1.10-1.27) \ddagger$ & 8 & 1.12 (1.07-1.17) & 6 & $1.28(1.15-1.42) \neq$ \\
\hline \multicolumn{9}{|l|}{ Sex } \\
\hline All & 9 & $1.08(1.02-1.14) \ddagger$ & 6 & $1.23(1.13-1.33)$ & - & - & - & - \\
\hline \multicolumn{9}{|c|}{$\begin{array}{l}\text { No. of covariablest adjusted } \\
\text { for in meta-regression }\end{array}$} \\
\hline$\geq 6$ & 10 & $1.03(1.00-1.05)$ & 3 & $1.13(1.04-1.23)$ & 6 & $1.07(1.04-1.11)$ & 5 & $1.13(1.07-1.19)$ \\
\hline$<6$ & 9 & $1.07(1.00-1.14)$ & 10 & $1.18(1.12-1.23) \ddagger$ & 9 & $1.12(1.06-1.18)$ & 7 & $1.31(1.20-1.43) \ddagger$ \\
\hline \multicolumn{9}{|c|}{$\begin{array}{l}\text { Note: } \mathrm{Cl}=\text { confidence interval, } \mathrm{CVD}=\text { cardiovascular diseases; } n=\text { number of studies with sex-specific results that were included in the analysis, RR = relative risk. } \\
{ }^{*} \text { All } p \text { values from meta-regression are not significant }(>0.05) \text {. } \\
\text { tCovariables were blood pressure, smoking, body mass index, physical activity, serum cholesterol or triglycerides, diabetes mellitus and blood glucose, alcohol use, } \\
\text { and education or social class. } \\
\text { fHeterogeneity was moderate }\left(l^{2} \text { value between } 50 \% \text { and } 75 \%\right) \text {. For RR values without this symbol, heterogeneity was low }\left(l^{2}<50 \%\right) .\end{array}$} \\
\hline
\end{tabular}




\section{Interpretation}

The multivariable-adjusted risk of coronary artery disease, stroke, sudden death, noncardiovascular diseases, all types of cancer and noncardiovascular diseases excluding cancer increased significantly, by $12 \%, 5 \%, 12 \%, 16 \%, 9 \%$ and $25 \%$, respectively, with every 10 beats/min increment in resting heart rate. The departure from a linear relation between resting heart rate and each of these end points was not significant.

These results may occur by various mechanisms. High resting heart rate could increase hemodynamic stress and shorten the diastolic phase, which could then increase mechanical load, tensile stress, low and oscillatory shear stress, blood pressure and cardiac work, thereby increasing oxygen consumption; these direct detrimental effects could cause coronary atherosclerosis and myocardial ischemia., $, 9,54$

High resting heart rate is a marker of sympathetic overactivity, which is associated with an increased risk of sudden death that usually results from ventricular fibrillation. ${ }^{55}$ Ischemic episodes are more likely to trigger serious arrhythmias in the context of high heart rate, and the beneficial effect of $\beta$-blockade on ventricular fibrillation may be mediated primarily by heart rate reduction. ${ }^{9}$ In addition, coronary lesions are present in most cases of sudden death in adults. ${ }^{56}$ Sympathetic overactivity may confer an increased risk of obesity that could induce insulin resistance, higher levels of uric acid, lipid abnormalities and hypertension. ${ }^{2}$ Therefore, these adverse events associated with sympathetic overactivity may account for the observed association between high heart rate and noncardiovascular diseases. High heart rate might be a marker of chronic stress and anxiety that may be related to an increase in the risk of cancer. ${ }^{45}$ In addition, common elements such as growth factors may be associated with hemodynamic parameters and the evolution of cancer. ${ }^{57}$

Although it seems desirable to maintain resting heart rate substantially below the traditionally defined tachycardia threshold of 90 or 100 beats/min, ${ }^{9}$ the results of this meta-analysis show that the desirable resting heart rate differs

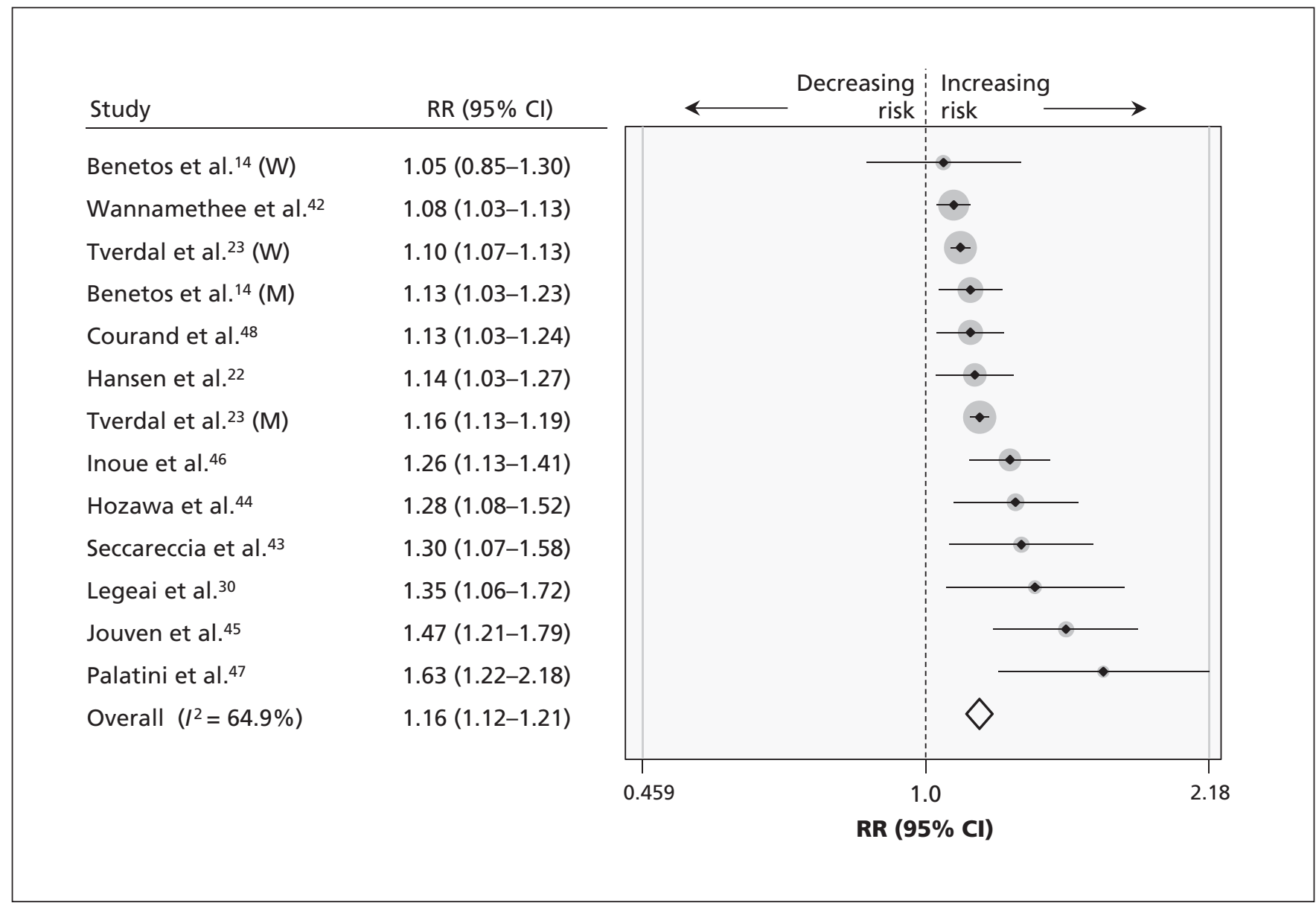

Figure 2: Forest plot of each increment in resting heart rate of 10 beats/min in relation to risk of noncardiovascular diseases. The size of each grey circle is proportional to the weight assigned to that study. Covariable-adjusted risk estimates were used because the raw numbers were not provided in the original studies. Note: $\mathrm{Cl}=$ confidence interval, $\mathrm{M}=$ men, $\mathrm{RR}=$ relative risk, $\mathrm{W}=\mathrm{women}$. 
with the end point of interest. Compared with 70 beats/min, a linear dose-response analysis indicated a significantly protective effect of lower resting heart rates on the risk of all-cause mortality in general populations in our previous study. ${ }^{6}$ The results of the current meta-analysis showed that, compared with 70 beats/min, lower resting heart rate was also associated with a significantly decreased risk of mortality from noncardiovascular diseases. These findings indicate the possibility that "the slower the heart

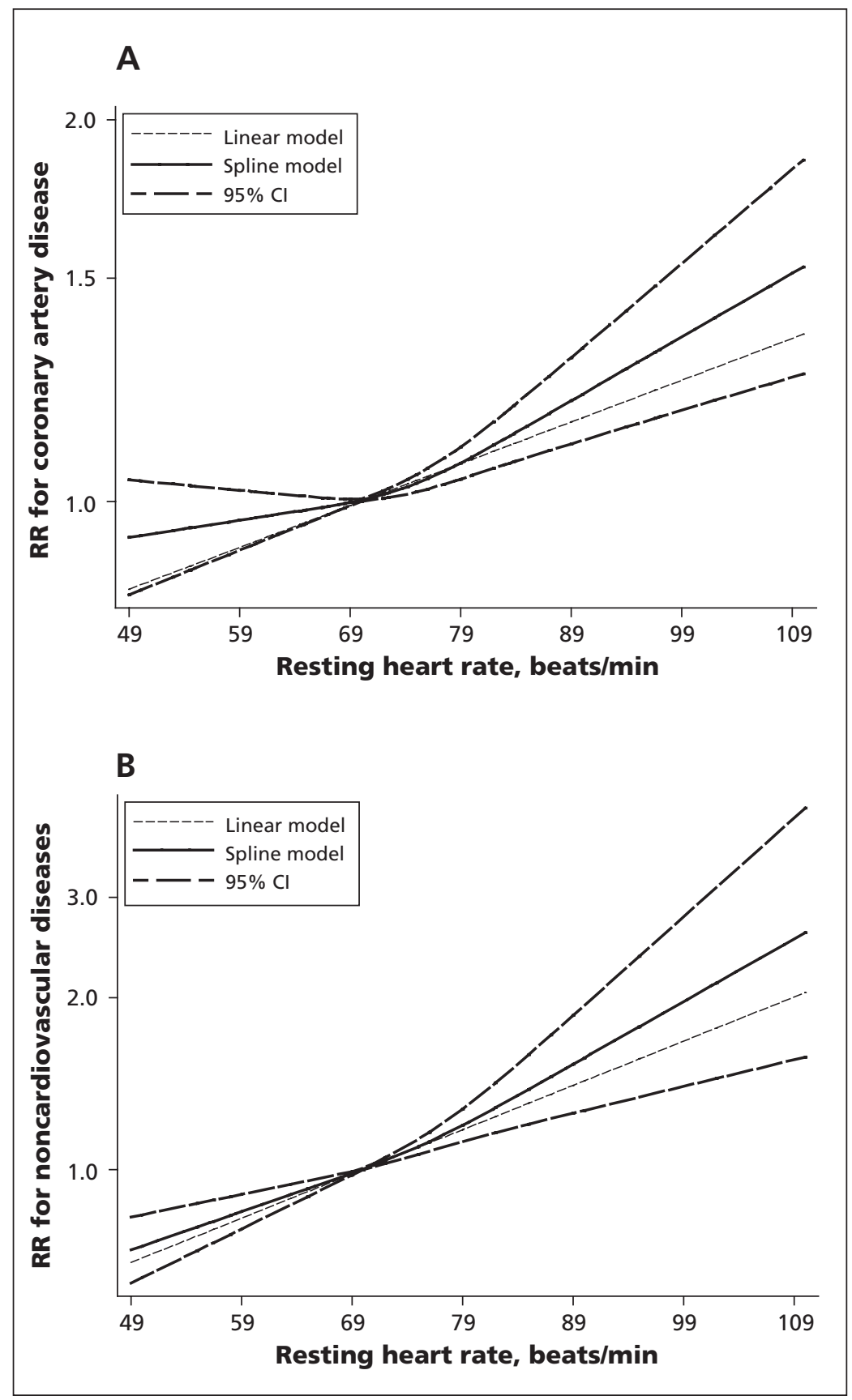

Figure 3: Dose-response analysis of resting heart rate with risk of (A) coronary artery disease and (B) noncardiovascular diseases. The solid line and the longdash lines represent the estimated relative risk (RR) and its $95 \%$ confidence interval $(\mathrm{Cl})$, respectively. The short-dash line represents the linear relation. rate, the better" 58 for all-cause mortality and mortality from noncardiovascular diseases in general populations.

We observed a significantly increased risk of total cardiovascular mortality at 90 beats/min in the previous meta-analysis. ${ }^{6}$ However, the current meta-analysis indicated that the association with stroke was weak, whereas resting heart rate had a significant positive association with coronary artery disease above a threshold value of about 80 beats/min (Appendix 6). At a resting heart rate above 60 beats/min, a linear association was observed between resting heart rate and heart failure, with an overall hazard ratio of 1.13 (95\% CI $1.07-1.18$, per 10 beats $/ \mathrm{min}$ increment). ${ }^{59}$ In addition to the various end points, demographic and measurement factors should also be taken into account when considering a desirable or optimal resting heart rate. ${ }^{9}$

\section{Limitations}

This study has some limitations. First, night-time heart rate has better prognostic value than resting heart rate in a population with no apparent heart disease $^{3}$ and in people with hypertension. ${ }^{60}$ In addition, ambulatory heart rate might have better predictive power than clinic-based resting heart rate; however, there was a high degree of correlation between these 2 measurements, and ambulatory heart rate did not add prognostic information beyond that provided by clinic heart rate. ${ }^{47}$ Although resting heart rate may change over time, a single measurement of resting heart rate was found to be as strong a predictor of cardiovascular outcomes as repeated measurements over the course of 8 years. ${ }^{34}$

The number of covariables and the extent to which the potential confounders were adjusted for varied across studies; as such, collaborative pooling of individual participant data would be a better way to explore the relations. Third, as shown in Appendix 4, some studies did not exclude participants with prevalent cardiovascular diseases and noncardiovascular diseases. As such, we were not studying the incidence of disease. However, we obtained similar cardiovascular-specific results after excluding participants with cardiovascular diseases at baseline.

Because of the small sample size, no association with heart failure was found in the sensitivity analysis. In addition, a positive association was detected in 2 studies $^{61,62}$ in general populations that did not meet the criteria for inclusion in this meta-analysis.

\section{Conclusion}

Resting heart rate was an independent predictor of coronary artery disease, stroke, sudden death and noncardiovascular diseases over all of the 
studies combined. When the analysis included only studies concerning general populations, resting heart rate was not associated with sudden death. Further studies are warranted to confirm the findings in patients with hypertension or diabetes (because of the importance of reducing heart rate in these patients) and to explore the association between resting heart rate and sudden death, specific types of cancer and other specific outcomes of noncardiovascular diseases.

Routinely measured resting heart rate is worth considering in risk prediction algorithms for coronary artery disease and cancer. Although there were no trials available focusing on the effect of heart rate reduction on outcomes in the general population, our results indicate the need to consider such a trial.

\section{References}

1. Valentini M, Parati G. Variables influencing heart rate. Prog Cardiovasc Dis 2009;52:11-9.

2. Palatini P. Heart rate and the cardiometabolic risk. Curr Hypertens Rep 2013;15:253-9.

3. Johansen CD, Olsen RH, Pedersen LR, et al. Resting, nighttime, and $24 \mathrm{~h}$ heart rate as markers of cardiovascular risk in middle-aged and elderly men and women with no apparent heart disease. Eur Heart J 2013;34:1732-9.

4. Jensen MT, Marott JL, Allin KH, et al. Resting heart rate is associated with cardiovascular and all-cause mortality after adjusting for inflammatory markers: the Copenhagen City Heart Study. Eur J Prev Cardiol 2012;19:102-8.

5. Ogliari G, Mahinrad S, Stott DJ, et al. Resting heart rate, heart rate variability and functional decline in old age. CMAJ 2015; 187:E442-9.

6. Zhang D, Shen X, Qi X. Resting heart rate and all-cause and cardiovascular mortality in the general population: a metaanalysis. CMAJ 2016;188:E53-63.

7. Perk J, De Backer G, Gohlke H, et al.; European Association for Cardiovascular Prevention \& Rehabilitation (EACPR); ESC Committee for Practice Guidelines (CPG). European guidelines on cardiovascular disease prevention in clinical practice (version 2012). The Fifth Joint Task Force of the European Society of Cardiology and Other Societies on Cardiovascular Disease Prevention in Clinical Practice (constituted by representatives of nine societies and by invited experts). Eur Heart J 2012;33:1635-701.

8. Goff DC Jr, Lloyd-Jones DM, Bennett G, et al.; American College of Cardiology/American Heart Association Task Force on Practice Guidelines. 2013 ACC/AHA guideline on the assessment of cardiovascular risk: a report of the American College of Cardiology/American Heart Association Task Force on Practice Guidelines. J Am Coll Cardiol 2014;63:2935-59.

9. Fox K, Borer JS, Camm AJ, et al.; Heart Rate Working Group. Resting heart rate in cardiovascular disease. J Am Coll Cardiol 2007;50:823-30.

10. Orsini N, Li R, Wolk A, et al. Meta-analysis for linear and nonlinear dose-response relations: examples, an evaluation of approximations, and software. Am J Epidemiol 2012;175:66-73.

11. Bekkering GE, Harris RJ, Thomas S, et al. How much of the data published in observational studies of the association between diet and prostate or bladder cancer is usable for metaanalysis? Am J Epidemiol 2008;167:1017-26.

12. Palatini P. Need for a revision of the normal limits of resting heart rate. Hypertension 1999;33:622-5.

13. Shaper AG, Wannamethee G, Macfarlane PW, et al. Heart rate, ischaemic heart disease, and sudden cardiac death in middleaged British men. Br Heart J 1993;70:49-55.

14. Benetos A, Rudnichi A, Thomas F, et al. Influence of heart rate on mortality in a French population: role of age, gender, and blood pressure. Hypertension 1999;33:44-52.

15. Greenland P, Daviglus ML, Dyer AR, et al. Resting heart rate is a risk factor for cardiovascular and noncardiovascular mortality: the Chicago Heart Association Detection Project in Industry. Am J Epidemiol 1999;149:853-62.

16. Reunanen A, Karjalainen J, Ristola P, et al. Heart rate and mortality. J Intern Med 2000;247:231-9.
17. Kado DM, Lui LY, Cummings SR; Study of Osteoporotic Fractures Research Group. Rapid resting heart rate: a simple and powerful predictor of osteoporotic fractures and mortality in older women. J Am Geriatr Soc 2002;50:455-60.

18. Okamura T, Hayakawa T, Kadowaki T, et al.; NIPPONDATA80 Research Group. Resting heart rate and causespecific death in a 16.5-year cohort study of the Japanese general population. Am Heart J 2004;147:1024-32.

19. Jouven X, Empana JP, Schwartz PJ, et al. Heart-rate profile during exercise as a predictor of sudden death. $N$ Engl $J$ Med 2005;352:1951-8

20. Savonen KP, Lakka TA, Laukkanen JA, et al. Heart rate response during exercise test and cardiovascular mortality in middle-aged men. Eur Heart J 2006;27:582-8.

21. Adabag AS, Grandits GA, Prineas RJ, et al.; MRFIT Research Group. Relation of heart rate parameters during exercise test to sudden death and all-cause mortality in asymptomatic men. Am J Cardiol 2008; 101:1437-43.

22. Hansen TW, Thijs L, Boggia J, et al.; International Database on Ambulatory Blood Pressure in Relation to Cardiovascular Outcomes Investigators. Prognostic value of ambulatory heart rate revisited in 6928 subjects from 6 populations. Hypertension 2008;52:229-35.

23. Tverdal A, Hjellvik V, Selmer R. Heart rate and mortality from cardiovascular causes: a 12 year follow-up study of 379,843 men and women aged 40-45 years. Eur Heart J 2008;29:2772-81.

24. Hsia J, Larson JC, Ockene JK, et al.; Women's Health Initiative Research Group. Resting heart rate as a low tech predictor of coronary events in women: prospective cohort study. BMJ 2009; 338:b219.

25. Mai JZ, Zhao LC, Liu XQ, et al. Association between heart rate and all-cause death and coronary event in the Chinese cohort: 16 years follow up results [article in Chinese]. Zhonghua Xin Xue Guan Bing Za Zhi 2009;37:750-3.

26. Batty GD, Shipley MJ, Kivimaki M, et al. Walking pace, leisure time physical activity, and resting heart rate in relation to disease-specific mortality in London: 40 years follow-up of the original Whitehall study. An update of our work with professor Jerry N. Morris (1910-2009). Ann Epidemiol 2010;20: 661-9.

27. Cooney MT, Vartiainen E, Laatikainen T, et al. Elevated resting heart rate is an independent risk factor for cardiovascular disease in healthy men and women. Am Heart J 2010;159:612619.e3.

28. Mao Q, Huang JF, Lu X, et al. Heart rate influence on incidence of cardiovascular disease among adults in China. Int $J$ Epidemiol 2010;39:1638-46.

29. Nauman J, Nilsen TI, Wisløff U, et al. Combined effect of resting heart rate and physical activity on ischaemic heart disease: mortality follow-up in a population study (the HUNT study, Norway). J Epidemiol Community Health 2010;64:175-81.

30. Legeai C, Jouven $X$, Tafflet M, et al. Resting heart rate, mortality and future coronary heart disease in the elderly: the $3 \mathrm{C}$ Study. Eur J Cardiovasc Prev Rehabil 2011;18:488-97.

31. Nauman J, Janszky I, Vatten LJ, et al. Temporal changes in resting heart rate and deaths from ischemic heart disease. JAMA 2011;306:2579-87.

32. Aladin AI, Whelton SP, Al-Mallah MH, et al. Relation of resting heart rate to risk for all-cause mortality by gender after considering exercise capacity (the Henry Ford exercise testing project). Am J Cardiol 2014;114:1701-6.

33. Floyd JS, Sitlani CM, Wiggins KL, et al. Variation in resting heart rate over 4 years and the risks of myocardial infarction and death among older adults. Heart 2015;101:132-8.

34. Ho JE, Larson MG, Ghorbani A, et al. Long-term cardiovascular risks associated with an elevated heart rate: the Framingham Heart Study. J Am Heart Assoc 2014;3:e000668.

35. Wang A, Chen $\mathrm{S}$, Wang $\mathrm{C}$, et al. Resting heart rate and risk of cardiovascular diseases and all-cause death: the Kailuan study. PLoS One 2014;9:e110985.

36. Woodward M, Webster R, Murakami Y, et al.; from the Asia Pacific Cohort Studies Collaboration. The association between resting heart rate, cardiovascular disease and mortality: evidence from 112,680 men and women in 12 cohorts. Eur J Prev Cardiol 2014;21:719-26.

37. Gillman MW, Kannel WB, Belanger A, et al. Influence of heart rate on mortality among persons with hypertension: the Framingham Study. Am Heart J 1993;125:1148-54.

38. Paul L, Hastie CE, Li WS, et al. Resting heart rate pattern during follow-up and mortality in hypertensive patients. Hypertension 2010;55:567-74.

39. Julius S, Palatini P, Kjeldsen SE, et al. Usefulness of heart rate to predict cardiac events in treated patients with high-risk systemic hypertension. Am J Cardiol 2012;109:685-92. 
40. Stettler C, Bearth A, Allemann S, et al. QTc interval and resting heart rate as long-term predictors of mortality in type 1 and type 2 diabetes mellitus: a 23-year follow-up. Diabetologia 2007;50: 186-94.

41. Poulter NR, Dobson JE, Sever PS, et al. ASCOT Investigators. Baseline heart rate, antihypertensive treatment, and prevention of cardiovascular outcomes in ASCOT (Anglo-Scandinavian Cardiac Outcomes Trial). J Am Coll Cardiol 2009;54:1154-61.

42. Wannamethee G, Shaper AG, Macfarlane PW. Heart rate, physical activity, and mortality from cancer and other noncardiovascular diseases. Am J Epidemiol 1993;137:735-48.

43. Seccareccia F, Pannozzo F, Dima F, et al.; Malattie Cardiovascolari Aterosclerotiche Istituto Superiore di Sanita Project. Heart rate as a predictor of mortality: the MATISS project. Am J Public Health 2001;91:1258-63.

44. Hozawa A, Inoue R, Ohkubo $\mathrm{T}$, et al. Predictive value of ambulatory heart rate in the Japanese general population: the Ohasama study. J Hypertens 2008;26:1571-6.

45. Jouven X, Escolano S, Celermajer D, et al. Heart rate and risk of cancer death in healthy men. PLoS One 2011;6:e21310.

46. Inoue R, Ohkubo T, Kikuya M, et al. Predictive value for mortality of the double product at rest obtained by home blood pressure measurement: the Ohasama study. Am J Hypertens 2012;25:568-75.

47. Palatini P, Thijs L, Staessen JA, et al.; Systolic Hypertension in Europe (Syst-Eur) Trial Investigators. Predictive value of clinic and ambulatory heart rate for mortality in elderly subjects with systolic hypertension. Arch Intern Med 2002;162: 2313-21.

48. Courand PY, Milon H, Gustin MP, et al. Effect modification of aortic atheroma on the prognostic value of heart rate in hypertension. J Hypertens 2013;31:484-91, discussion 491.

49. Gillum RF, Makuc DM, Feldman JJ. Pulse rate, coronary heart disease, and death: the NHANES I Epidemiologic Follow-up Study. Am Heart J 1991;121:172-7.

50. O'Neal WT, Qureshi WT, Judd SE, et al. Heart rate and ischemic stroke: the REasons for Geographic And Racial Differences in Stroke (REGARDS) study. Int J Stroke 2015;10:1229-35.

51. Hisamatsu T, Miura K, Ohkubo T, et al.; NIPPON DATA80 Research Group. High long-chain n-3 fatty acid intake attenuates the effect of high resting heart rate on cardiovascular mortality risk: a 24-year follow-up of Japanese general population. J Cardiol 2014;64:218-24.
52. Thomas F, Guize L, Bean K, et al. Pulse pressure and heart rate: Independent risk factors for cancer? J Clin Epidemiol 2001;54:735-40

53. Kristal-Boneh E, Silber H, Harari G, et al. The association of resting heart rate with cardiovascular, cancer and all-cause mortality. Eight year follow-up of 3527 male Israeli employees (the CORDrosoph Inf Serv Study). Eur Heart J 2000;21:116-24.

54. Palatini P. Elevated heart rate in cardiovascular diseases: a target for treatment? Prog Cardiovasc Dis 2009;52:46-60.

55. Gopinathannair R, Martins JB. Predicting sudden cardiac death in healthy humans: Is there more to autonomic balance than we know? Heart Rhythm 2008;5:306-7.

56. Farb A, Tang AL, Burke AP, et al. Sudden coronary death. Frequency of active coronary lesions, inactive coronary lesions, and myocardial infarction. Circulation 1995;92:1701-9.

57. Isner JM. Cancer and atherosclerosis: the broad mandate of angiogenesis. Circulation 1999;99:1653-5.

58. Reil JC, Böhm M. BEAUTIFUL results - the slower, the better? Lancet 2008;372:779-80.

59. Khan H, Kunutsor S, Kalogeropoulos AP, et al. Resting heart rate and risk of incident heart failure: three prospective cohort studies and a systematic meta-analysis. J Am Heart Assoc 2015;4:e01364

60. Palatini P, Reboldi G, Beilin LJ, et al. Predictive value of night-time heart rate for cardiovascular events in hypertension. The ABP-International study. Int J Cardiol 2013;168:1490-5.

61. Dyer AR, Persky V, Stamler J, et al. Heart rate as a prognostic factor for coronary heart disease and mortality: findings in three Chicago epidemiologic studies. Am J Epidemiol 1980;112:736-49.

62. Kannel WB, Kannel C, Paffenbarger RS Jr, et al. Heart rate and cardiovascular mortality: the Framingham Study. Am Heart J 1987;113:1489-94.

Affiliation: Department of Epidemiology and Health Statistics, Medical College of Qingdao University, Shandong, Qingdao, China

Contributors: All of the authors contributed substantially to the conception and design of the study, the acquisition of data, and the analysis and interpretation of data. All of the authors drafted the article, revised it critically for important intellectual content, gave final approval of the version to be published and agreed to act as guarantors of the work. 